\title{
Neoplasias and B-cell precursors
}

\section{from Maxime Seligmann}

THE earliest recognisable cells within the B-cell differentiation pathway are known as pre-B cells. They are found in the fetal liver of rabbits, mice and men and are characterised by the presence of intracytoplasmic $\operatorname{IgM}$ and the lack of surface receptors ${ }^{1-3}$. In adults, pre-B cells are found almost exclusively in the bone marrow ${ }^{4}$ IgM can be datected by immunofluorescence techniques in the cytoplasm of most, if not all, large rapidly dividing pre-B cells and their small non-dividing pre-B cell progeny ${ }^{5}$, with an unusual perinuclear and reticular staining pattern. Pre-B cells are the progenitors of surface $\mathrm{Ig}$ positive B lymphocytes but, because they do not express functional immunoglobulin receptors on their surface, it can safely be assumed that antigens do not influence the diversity of immunoglobulins produced by pre-B cells. Various studies suggest that clonal diversification is accomplished by the pre-B cell stage. For example, individual pre-B cells show allelic exclusion in rabbits heterozygous for kappa chain allotypes ${ }^{6}$. In myeloma patients, antibodies specific for idiotypic determinants of the myeloma globulin stain bone marrow cells with pre-B cell characteristics ${ }^{7}$; this finding provides evidence that pre-B cells belong to the neoplastic clone and suggests that $\mathrm{V}-\mathrm{C}$ joining has occurred at this stage.

Several recent studies have shown that some murine and human neoplasias involve such early B-cell precursors which produce cytoplasmic immunoglobulin in the absence of membranebound immunoglobulin molecules. The Abelson murine leukaemia virus complex, which consists of a replicationdefective virus and its helper Moloney leukaemia virus, causes thymus-independent lymphomas in $\mathrm{Balb} / \mathrm{c}$ mice, and several characteristics suggested that these tumours were related to the B-cell lineage ${ }^{8}$. Two independent studies $^{9,10}$ have recently provided evidence that several neoplastic cell lines resulting from in vivo or in vitro transformation by Abelson virus have features indicative of early maturation compartments in the Blymphocyte lineage. On the other hand, two human lymphoid cell lines (Raji and T51) were also shown to express characteristics of early B-cell precursors ${ }^{11}$. Finally the

M. Seligmann is Professor of Immunology at the University of Paris and Head of the INSERM Unit of Immunochemistry and Immunopathology at the Hospital Saint Louis. leukaemic cells of some patients with acute lymphoblastic leukaemia also display features thought to be characteristic of pre-B cells. This pre-B cell phenotype is not uncommon because it was found in four of 22 patients in the initial report by Vogler et al. ${ }^{12}$ and in 10 of 68 patients in the subsequent series of Brouet et al. ${ }^{13}$.

The results of immunofluorescence and immunoglobulin synthesis studies suggest that the maturation arrest in these various neoplastic cells may occur at slightly different steps in the early stages of the B-cell pathway. Early studies indicated that normal pre-B cells produce complete monomeric IgM molecules with both $\mu$ and light chain $^{1,2}$. In contrast, no light chain determinants could be detected by immunofluorescence in most human leukaemic pre-B cells ${ }^{13}$. This negative finding could be due to limitations of immunofluorescence technology because, in the human cultured cell lines mentioned above, light chains could not be detected by immunofluorescence but were found at the ultrastructural level by an immunoperoxidase method $^{11}$. It should be noted, however, that the number of normal pre-B cells containing detectable light chain determinants is lower than the number of such cells with detectable $\mu$ chains ${ }^{14}$. This discrepancy and the findings in acute lymphoblastic leukaemia are consistent with the possibility that there is an asynchronous onset of heavy and light chain synthesis. The data reported by Siden et al..$^{10}$ support this hypothesis because most Abelson-virus-induced cell lines synthesise a $\mu$ chain but no

\footnotetext{
Raff, M. C., Megson, M., Owen J. J. T. \& Cooper, M. D. Nature 259, 224-226 (1976). Melchers, F., Andersson, J. \& Philips, R. A Cold Spring Harb. Symp. quant. Biol. 41. 147-150 (1977)

3. Gathings, W. E., Lawton, A. R. \& Cooper,
M. D. Europ. J. Immun. 7, 804-810 (1977). M. D. Europ. J. Immun. 7, 804-810 (1977)
Pearl. E. R. et al. J. Immun. 120, 1169-1175 (1978)

Owen, J. J. T., Wright, D. E., Habu, S. Raff, M. C. \& Cooper M. D. J Immun. 118, 2067-2071 (1977).

6. Hayward, A. R., Simons, M. A., Lawton, A. R., Mage, R. G. \& Cooper, M. D J. exp. Med. 148, 1367-1377 (1978).

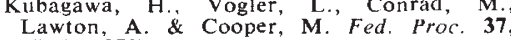
$1765(1978)$

8. Abelson. H. T. \& Rabstein, L. S. Cancer Res. 30, 2213-2222 (1970)

. Boss, M. Greaves, M. \& Teich, N. Nature

10. Siden, E. J.. Baltimore, D., Clark, D. \& Rosenberg, N. E. Cell 16. 389-396 (1979).

Reyes, F. \& Fellous, M. in Huntan Lymphocyte Differentiation: its Application to Cancer (ed. Serrou, B. \& Rosenfeld, C.) 345-35? (North Holland, Amsterdam, 1978).

12. Vosler. L. B. et al. New Engl. J. Med. 298 872-878 (1978)

Brouet, J. C. et al. Blood (in the press).

14. Cooper, M. D., Burrows, P. D. \& Lawton, A. R. in The Immune System: Functions and Therapy of Dystunction (Academic, New York, in the press).

15. Silverstone, A. E., Rosenberg, N. \& Baltimore, D. in Cold Soring Harbor Conf Cnll Profiferation, 5 (eds Clarkson, B. Till. J. E. \& Marks, P. A.) 432-452 (Col Spring Harbor Press, New York. 1978).
Baltimore, D. Nature 248, 409-41i (1974)
}

detectable light chain. This $\mu$-only phenotype was stable on subcloning. Cultures in which synthesis of both $\mu$ and $\kappa$ chains occurred showed a rapid loss of $\kappa$ chain synthesis. One line was studied in detail: the intracytoplasmic molecules represented glycosylated $\mu$ chain dimers which were not secreted. Light chain synthesis could not be induced by reducing the growth rate of the cells, a procedure that resulted in increased $\mu$ chain synthesis. In contrast to these findings, another Abelsonvirus-derived line studied by the same authors produced only $\kappa$ chains. It should be emphasised that the biosynthesis experiments showed that the cytoplasmic extract contained, in addition to the $\kappa$ chain band, a slower band which comigrated with a precursor polypeptide. It is interesting in this respect that the intracytoplasmic IgM of the human lines was not located inside endoplasmic reticulum but at the level of free polyribosomes ${ }^{11}$ and that these lines produce abnormally large Ig polypeptide chains (unpublished results of P. Guglielmi and J. L. Preud'homme). The two Abelson-virus-transformed cell lines studied by Boss et al. ${ }^{9}$ apparently synthesised monomeric IgM with both $\mu$ and light chains. However, most cells in both lines were presumably less mature than pre-B cells because they were negative for cytoplasmic IgM but could be induced to express IgM positivity by several compounds such as lipopolysaccharide, DMSO and butyric acid. The human lymphoid cell lines are presumably slightly more differentiated than bona fide pre-B cells because they bear Ia-like determinants, they secrete polymeric IgM molecules (instead of monomeric IgM in normal pre-B cells ${ }^{2}$ ) and they become able to produce membrane-bound immunoglobulin molecules in certain conditions (unpublished results of P. Guglielmı and J. L. Preud'homme).

Another point of interest is that human pre-B leukaemic cells in a fair percentage of patients ${ }^{13}$, as well as several Abelson virus-induced tumours $^{15}$ and normal pre-B cells (G. Janossy, personal communications), were shown to contain low but detectable levels of terminal deoxynucleotidyl transferase. This enzyme was initially considered as characteristic for thymic and prethymic cells but it is probably present in progenitors of all lymphoid cells, a finding which might be related to the possible role of this enzyme in the generation of somatic mutations ${ }^{16}$

The availability of tumour cells and continuous lines corresponding to early precursors of the $B$ lineage lymphoid cells should be useful for the study of immunoglobulin gene diversification and expression. 